\title{
Application of Scenario Simulation Method in Teaching of Pharmaceutical Marketing
}

\author{
Jun $\mathrm{Li}^{1,2, \mathrm{a}}$ and $\mathrm{Han} \mathrm{He}^{3, \mathrm{~b} *}$ \\ ${ }^{1}$ Rongzhi College of Chongqing Technology And Business University, Chongqing 400067, China \\ ${ }^{2}$ School of Biological and Chemical Engineering,Chongqing University of Education, Chongqing \\ 400067, China \\ ${ }^{3}$ Chongqing Collaborative Innovation Center for Functional Food, Chongqing University of Education, \\ Chongqing 400067, China \\ a247491362@qq.com, bene771771@hotmail.com \\ *The corresponding author
}

Keywords: Pharmaceutical marketing; Scenario teaching method; Role play

\begin{abstract}
Based on the cultivating target of application-oriented universities for students, this paper analyzes the main problems of "pharmaceutical marketing" existing in the aspects of course construction, teacher's teaching concept, student's leading role and evaluation method etc., and discusses the procedure, contents and key points of scenario simulation method (role play) applied in this course so as to improve the learning interest and effect of students.
\end{abstract}

\section{Introduction}

Pharmaceutical marketing is a core course with more theory and practice in the (pharmaceutical marketing field) major of our biological and chemical engineering department. Its goal is to make students to learn to analyze the pharmaceutical marketing environment, develop the marketing strategy of pharmaceutical products and grasp the basic pharmaceutical sales skill on the basis that students master certain knowledge of medicine, pharmacology and marketing. However, at present stage, more problems exist in the pharmaceutical marketing teaching of many colleges and universities. The demand to cultivate the applied talents with high skill cannot be met. Consequently, how to meet the demand to cultivate applied undergraduate talents and achieve the course goal of pharmaceutical marketing is a vital subject required to be solved and discussed deeply.

\section{Problems Existing in Teaching of Pharmaceutical Marketing}

Course Construction Lags and Pertinence of Teaching Material Are Poor. At present, the course construction of pharmaceutical marketing lags relatively. Besides, the teaching material is lack of pertinence. The existing teaching materials of pharmaceutical marketing published by different presses are compiled based on the theory of classic marketing teaching material. The systematicness of discipline is emphasized in the arrangements and the logicality is focused in the contents. However, the teaching characteristics that the application-oriented universities take the job demand as orientation, the professional practical ability as goal and the practical and sufficient contents as principle are ignored. In addition, the matched resources of teaching materials are lack. Especially, the required case resources of marketing course are antiquated relatively. The combination with the working practice of pharmaceuticals industry is not close.

Teacher's Teaching Concept Is Antiquated and the Teaching Method Is Single. Pharmaceutical marketing is not only a theoretical discipline but also an applied discipline. Therefore, it has a high requirement for teachers, including the solid knowledge in medicine and pharmacy, knowledge in marketing and the rich practical experience in pharmaceutical marketing. However, the professional background of most teachers is single. They are lack of practical experience in this industry. In the teaching process, the phenomenon that the teaching contents are constrained by 
textbooks and the theoretical knowledge divorces from enterprise's practical situation often appears. Some teachers neglect or are not active to cultivate the students' skills subjectively, and lack of the cultivating method for skills objectively. The teaching is vapid and dull. Although some teachers have adopted the case teaching methodology, the problems that the case adopted is not new, the analysis and discussion are not deep, and the degree of students' participation is low etc. still exist. The real effect of case teaching cannot be reached.

Learning Initiative Is not High and the Principal Role of Students Is not Obvious. The traditional "PPT + classroom lecture" teaching method is teacher-centered, under which the unilateral communication plays a dominant role, students are in the passive learning state and the leading role of students is ignored. The students' participation is low and the learning atmosphere, dreary, so the learning initiative of students is not high and the learning effect, not optimistic.

Evaluation Method Is Lack of Scientificity. In the teaching process, assessment is an important link as well as the means to check and evaluate the learning effect of students. At present, a traditional method, written examination is mainly adopted to assess the specialized courses of our university. Although it can well check the mastery of students for theoretical knowledge, it ignores the practical ability of students. It cannot evaluate the real learning effect of students scientifically, objectively and comprehensively. Moreover, the orientation that students "value knowledge, result and theory, and ignore ability, process and practice" may occur easily, which is contrary to the cultivating target of applied undergraduate.

\section{Practice of Scenario Simulation Method in the Teaching of Pharmaceutical Marketing}

Concept and Connotation of Scenario Simulation Method. In recent-year teaching practice, the author focuses on the goal of this course to lay emphasis on the individualized quality education and try to use the multiple teaching methods so as to improve the teaching effect of pharmaceutical marketing, such as module teaching method, case teaching method and scenario simulation method, among which scenario simulation method can make the leading role of students to give full play, stimulate the learning interest of students better and contribute to the cultivation of students' practical ability.

Scenario simulation method refers that teachers design the targeted scenario based on the course goal and teaching contents to let student play the situational role and simulate the scenario process so that the students grasp the knowledge and improve their ability in the process of high simulation [1]. This method makes students to be on the scene personally. The operability is highlighted. It strives for interestingness and effectiveness and also taking the theory into consideration. It is characterized by the close integration between theory and practice, the deep participation between teachers and students, and high integration between students experience and simulated situation etc [2].

The core of scenario simulation teaching method is to create scenario. The key point is the role play. In the scenario highly close to real work, make students to personally experience the psychology, motion, attitude and behavioral preference etc. of role they play so as to stimulate their sense of participation and learning interest, deepen their understanding for theoretical knowledge and exercise their ability to flexibly use the learned knowledge.

In the teaching of pharmaceutical marketing, teachers can create the scenario like drugstore retail, customer visit and academic conference etc. to make students to play the role of consumer, doctor, salesperson and sales representative etc. respectively and solve some actual marketing problems. When applying scenario simulation teaching method, it is required to be based on certain material conditions and follow certain rules and implementation procedures. "Drugstore retail module" in pharmaceutical marketing will be taken as example to illustrate as below [3].

Procedure and Contents of Scenario Simulation Teaching Method. Scenario setting: The premise to apply the scenario simulation teaching method is that teachers set a representative social scenario. Try to choose the typical design scenario with real occupational question, consistent with the teaching contents so as to make students to have a more profound understanding for the meaning 
of occupational post and the professional sense of approval [4-6]. Meanwhile, according to the ability development stage of students, choose the case and the scenario. So in the module of "drugstore retail", we have designed a typical scenario that the different consumer groups buy medicine in the drugstore, which is implemented in the simulation drugstore. Role play: the preparatory work prior to the role play is more sufficient, the implementation of role play, more successful and the teaching effect more obvious [7-9]. The preparatory work mainly includes the following three parts: (1) Teachers and students analyze the scenario together. Have a definite understanding for the contents and the procedure of role play, the characteristics of each role and the problems needed to be solved etc. through discussion. (2) Assign the role. According to the demand of scenario, we have designed the roles like consumers (the young, the middle-aged, the old and children) and salesperson of drugstore etc. so that as many students as possible can participate in it. (3) The preparations of role play, including various resources required in the teaching activity and the arrangement of environment. The simulated scenario should be close to the reality as far as possible. The creation of atmosphere also should be lifelike to the greatest extent so that the students can get into the character as soon as possible and stimulate their interest and creativity. The role players get into the scenario set in advance to play their own role. In the performance process, the extemporaneous play is allowed if only it is consistent with the scenario set. It is not necessary to rigidly adhere to the established plot. In addition, in the watching process, teachers and students are required not to interrupt the performance at random. They should observe and evaluate the skill of role players who use the pharmaceutical knowledge to sell the drug based on the characteristics of consumers. Summary and evaluation: After the performance is completed, teachers and students should make a summary and evaluation for the role play. First, let students to make communication and discussion, share their experience and feeling in the performance, and analyze the problems existing in the performance. Then teachers make a summary and evaluation. When summarizing and evaluating, the teacher should guide the students to use their learned knowledge to analyze and solve the practical problems in accordance with the scenario set so that the perceptual knowledge of students rises to the rational knowledge $[10,11]$.

\section{Thinking and Conclusion}

In order to ensure the scenario simulation teaching method can reach the expected teaching effect, the design and control of role play is the key point. The following four points are required to pay attention.

(1) The preparation prior to the role play must be sufficient. Teachers are required to design the scenario based on the characteristics of teaching contents, guide students to study the case, analyze the role and simulate the real environment. Students are required to actively cooperate with teachers, grasp the words and deeds as well as attitude of character, prepare the dialogue of character and rehearse seriously. Otherwise, the role play is inclined to become formalistic. The teaching goal cannot be reached. Moreover, students may be disgusted with it more. The effect will be opposite to what we wish.

(2) The role play should not be applied alone. It must be used with other teaching methods together. For instance, before implementing the role play, the lecturing method and the case analysis method etc. can be adopted so that students have a perceptual knowledge for the theoretical knowledge.

(3) The role play should let as many students as possible to participate. The monodrama by individual student should not be advocated. It is required to create a relaxed, active and positive learning atmosphere.

(4) The evaluation for role play should be diversified. The combined methods like mutual group evaluation, mutual inter-group evaluation, student self-evaluation and teacher evaluation should be adopted. In addition of role performance, the evaluation contents also should be focused on the evaluation for knowledge and ability applied in the process of performance. In addition of the result evaluation, the evaluation for the process also should be paid attention. 
In the process of implementation, the scenario simulation teaching method also has exposed certain problems. For example, too high interestingness of activity interferes with the completion of learning task. The indulging in performance makes students to ignore their learning target. Some students highlight themselves excessively in the performance. The teachers' evaluation is not very objective due to their own standpoint. The software and hardware of training room is to be improved etc. This requires teachers to optimize the detailed problems when applying the scenario simulation teaching method. In a word, the relation between students and teachers has been improved after adopting the scenario simulation teaching method in the teaching of pharmaceutical marketing. Meanwhile, the transformation from the teacher-centered classroom teaching to the student-centered one also has been realized. The practical ability and comprehensive quantity of students both have been improved.

\section{References}

[1] Z.Y. Zeng, Research on the simulated teaching of the scence in management science, J. High. Educ. Res. 32 (2009) 65-66.

[2] F.L. Du, Z.Z. Zhang, Application of cases-teaching-approach on medicine marketing, J. Henan Med. Coll. Staff Work. 23 (2011) 591-594.

[3] W. Huang, J.M. Swaminathan, Introduction of a second channel: Implications for pricing and profits, Eur. J. Oper. Res. 194 (2009) 258-279.

[4] J. Liu, The application of scenario simulation teaching method in teaching, J. Changchun Univ. 22 (2012) 912-914.

[5] W.J. Wu, A human resource management teaching reform research based on scenario simulation, J. Weinan Nor. Univ. 30 (2015) 52-56.

[6] J.L. Chang, Y. Wang, F.X. Zhao, Application of scenario simulation in medical and surgical nursing teaching, China High. Med. Educ. 2010 (2010) 97-98.

[7] Y. Baruch, Role-play teaching, Manage. Learn. 37 (2006) 43-61.

[8] B. Joyner, L. Young, Teaching medical students using role play: twelve tips for successful role plays, Med. Teach. 28 (2006) 225-229.

[9] C. Lane, K. Hood, S. Rollnick, Teaching motivational interviewing: using role play is as effective as using simulated patients, Med. Educ. 42 (2008) 37-44.

[10] S. Cohen, Williamson on gettier cases in epistemic logic and the knowledge norm for rational belief: a reply to a reply to a reply, Inquiry 56 (2013) 400-415.

[11] R. Mahajan, N.R. Singh, J. Singh, A. Dixit, A. Jain, A. Gupta, Current scenario of attitude and knowledge of physicians about rational prescription: A novel cross-sectional study, J. Pharm. Bioallied Sci. 2 (2010) 132-136. 